\title{
Do uso fraudulento das cooperativas de trabalho no Brasil
}

\author{
Rocco Antonio Rangel Rosso Nelson* \\ Professor do Instituto Federal do Rio Grande do Norte-IFRN (Brasil)
}

Recibido: 10-1-2014

Aceptado: 17-9-2014

Sumario: 1. Das considerações iniciais. 2. A cooperativa de trabalho (fraudulenta) como instrumento para alijamento dos direitos sociais do empregado. 2.1. Da cooperativa de trabalho. 2.2. Dos elementos configuradores da licitude da cooperativa de trabalho. 2.3. Requisito formal trazido pela Lei $n .{ }^{\circ} 12.690 / 12$ para licitude da cooperativa de trabalho de prestação de serviço. 2.4. Composiç̧ão de um arcabouço de prerrogativas sociais em favor do sócio/cooperativo. 3. Considerações finais. Referências.

Resumo: 0 arcabouço normativo protetivo que reveste o trabalhador, o qual possui a finalidade de humanizar e dar um conteúdo ético social ao lucro proveniente da atividade capitalista, é constantemente atacado pelo empresariado que busca, de toda forma, reduzir os custos com os direitos básicos/fundamentais do trabalho, fruto de um processo histórico de constitucionalização. Um dos subterfúgios utilizados tem sido a constituição fraudulenta de cooperativas de trabalho, com o fim de desnaturar um verdadeiro vínculo empregatício, onde o empregador simularia essa relação por meio de um contrato de prestação de serviço com a cooperativa de trabalho, sendo esta uma intermediária de mão-de-obra, indo contra todos os postulados axiológicos do cooperativismo. A pesquisa em tela faz uso de uma metodologia de análise qualitativa, usando-se os métodos de abordagem hipotético-dedutivos de caráter descritivo e analítico, tendo por fundo analisar os novos enunciados normativos da Lei n. 12.690 de 2012, que veio criar o marco regulatório das cooperativas de trabalho com fito de proporcionar uma clareza na relação jurídica entre o contratante e o contratado de forma a distinguir a relação empregatícia e a relação de prestação de serviço feito por uma cooperativa, de sorte a desestimular a prática odiosa do desvirtuamento do cooperativismo.

Palavras-chave: Cooperativas de trabalho. Fraude. Relação de emprego. Efetivação dos direitos sociais.

* Especialista em Direito e Cidadania pela Escola Superior do Ministério Público. Especialista em Direito Penal e Criminologia pela Universidade Potiguar. Mestre em Direito Constitucional pela UFRN. Ex-professor do curso de direito e de diversos cursos tecnológicos e da pós-graduação do Centro Universitário FACEX. Professor de Direito do Instituto Federal do Rio Grande do Norte-IFRN. 
Resumen: El marco normativo que cubre el trabajador de protección, el cual tiene el propósito de humanizar y el contenido ético de los beneficios sociales de la actividad capitalista, es constantemente atacada por el negocio que busca, por todos los medios, reducir los costos de los derechos básicos fundamentales / trabajo, el resultado de un proceso histórico de constitucionalización. Uno de los subterfugios utilizados ha sido la creación de cooperativas de trabajo fraudulentas, con el fin de desnaturalizar una verdadera relación laboral cuando el empleador simular esta relación a través de un contrato de servicio con la cooperativa, que es un intermediario mano de obra, en contra de todos los supuestos axiológicos de cooperación. Investigación en la pantalla hace uso de una metodología para el análisis cualitativo, utilizando los métodos de enfoque hipotético-deductivo, descriptivo y analítico, con el fondo de analizar las nuevas disposiciones normativas de la Ley N. ${ }^{\circ} 12.690$ de 2012, que creó el marco normativo trabajo cooperativo con el objetivo de proporcionar claridad sobre la relación jurídica entre el contratista y el contratista con el fin de distinguir la relación de trabajo y la relación de servicio realizada por una cooperativa, con el fin de desalentar la odiosa práctica de la coloración de la cooperativa.

Palabras clave: Cooperativas de trabajo. Fraude. Relación laboral. El cumplimiento de los derechos sociales.

Abstract: The normative framework that covers the protective worker, which has the purpose of humanizing and ethical content to the social profit from the capitalist activity is constantly attacked by entrepreneurs seeking in every way to reduce costs with the basic rights/fundamental labor, the result of a historical process of constitutionalization. One of the subterfuges used has been the creation fraudulent labor cooperatives, in order to denature a true employment relationship where the employer simulate this relationship through a contract of service with the cooperative, which is a intermediate hand labor, against all tenets of cooperative axiological. Research on screen makes use of a methodology for qualitative analysis, using the methods of approach hypothetical-deductive, descriptive and analytical, with the background to analyze the new normative provisions of Law n. ${ }^{\circ} 12,690$ of 2012, which created the milestone regulatory cooperative work with aim to provide clarity on the legal relationship between the contractor and the contractor in order to distinguish the employment relationship and the relationship of service made by a cooperative, so as to discourage the abhorrent practice of coloring the cooperative.

Keyword: Work cooperatives. Fraud. Employment relationship. Fulfillment of social rights. 


\section{Das considerações iniciais}

O parágrafo único do art. 442 da Consolidação das Leis do Trabalho possuía o seguinte enunciado normativo: «Qualquer que seja o ramo de atividade da sociedade cooperativa, não existe vínculo empregatício entre ela e seus associados, nem entre estes e os tomadores de serviços daquela». ${ }^{1}$

A partir do conteúdo redacional extraído do artigo supra, constataram-se condutas sinuosas de empresários, com o fim de burlar a envergadura normativo protecionista dada ao trabalhador empregado, de contratar parte significativa da mão-de-obra, necessária ao empreendimento empresarial, via cooperativa de trabalho (cooperativas de mão de obra²). ${ }^{3}$

Sobre o art. 442 da Consolidação das Leis do Trabalho, assim se manifesta Delgado:

O objetivo da lei foi retirar do rol empregatício relações próprias às cooperativas - desde que não comprovada a roupagem ou utilização meramente simulatória de tal figura jurídica.

Ou seja: a lei favoreceu o cooperativismo, ofertando-lhe a presunção de ausência de vínculo empregatício; mas não lhe conferiu um instrumental para obrar fraudes trabalhistas. Por isso, comprovado que o envoltório cooperativista não atende às finalidades e princípios inerentes ao cooperativismo (princípio da dupla qualidade e princípio da retribuição pessoal diferenciada, por exemplo), fixando, ao revés, vínculo caracterizado por todos os elementos fático-jurídicos da relação de emprego, esta deverá ser reconhecida, afastando-se a simulação perpetrada. ${ }^{4}$

Não eram situações raras, principalmente nos rincões do Brasil, fruto da sua dimensão continental, de que empresários fomentassem a

1 Redação semelhante a do art. 90 da lei n. ${ }^{0}$ 5.764/71. Art. 90. Qualquer que seja o tipo de cooperativa, não existe vínculo empregatício entre ela e seus associados.

2 Cf. Godinho Delgado, Mauricio. Curso do Direito do Trabalho. 10. ed. São Paulo: LTr, 201, p. 327.

3 "As relações de trabalho do cooperado também não se encontram abrangidas pelo Direito do Trabalho, salvo se desvirtuadas de seus objetivos, o que ocorre com frequência, reclamando, inclusive, a eficiente atuação do Ministério Público do Trabalho, na propositura de ação civil pública na Justiça do Trabalho, em defesa dos interesses individuais homogêneos» (grifos nossos). (Monteiro de Barros, Alice. Curso do Direito do Trabalho. $7 .^{\circ}$ ed. São Paulo: LTr, 2011, p. 182).

4 Godinho Delgado, Mauricio. Curso do Direito do Trabalho. 10. ed. São Paulo: LTr, 2008, p. 327. 
criação de cooperativas de trabalho, impondo aos trabalhadores, como condição de contração, que se associassem à cooperativa.

Coteje que a constituição dessas cooperativas de trabalho tinha por real finalidade mascarar uma efetiva relação de emprego, de tal sorte a enquadrar aquele trabalhador como um "autônomo», o que vinha por reduzir significativamente o custo social com o trabalhador, pois como o mesmo seria "empregado», não faria jus a $13 .^{\circ}$ salário, piso salarial, hora extra, adicional noturno, férias, abono de férias, fundo de garantia de tempo de serviço, dentre outros. ${ }^{5}$

Não só havia uma redução drástica com o custo das obrigações trabalhistas, como, também, tributário.

Isso ocorre pelo fato de que uma das contribuições sociais do empregador para a seguridade social seria a contribuição patronal, a qual possui uma alíquota de $20 \%$ incidente sobre a folha de salários (base de cálculo). ${ }^{6}$ Ao contratar uma cooperativa, não se pode falar de salário, sendo a contraprestação financeira paga à cooperativa não incidente na base de cálculo da contribuição patronal.

Como o empresário está por contratar os serviços de uma cooperativa de trabalho, a Lei n. ${ }^{\circ} 8.212 / 91$, que trata do custeio da seguridade

5 «No intuito de se tomarem mais competitivas, como exigência do mercado, as empresas procuram reduzir os custos da produção por diversos meios, dentre os quais o rebaixamento dos salários, a extinção de vantagens obtidas pelos trabalhadores e de postos de trabalho, sem perspectiva de recuperação. Daí, o desemprego estrutural, que resulta em miséria, com reflexos no bem-estar e na segurança da sociedade de risco cara ao Estado Democrático de Direito.

Diante disso, surgem empreendimentos que assumem a feição de concorrentes do sistema capitalista tradicional. Trata-se das denominadas empresas de economia social ou solidária, que se situam entre as instituições públicas e o mercado e compõem o denominado «Terceiro Setor». Fundam-se na autogestão, na solidariedade e na democratização das relações de trabalho, ao mesmo tempo em que produzem resultados econômicos significativos. Esse perfil é também o das cooperativas, consideradas empresas de economia social, pois geram emprego e renda, enquanto produzem efeitos econômicos estruturantes». (Soares Filho, José. Sociedade Pós Industrial. Os impactos da globalização na Sociedade, no Trabalho, na Economia e no Estado. Curitiba: Juruá, 2007, p. 19).

6 Lei n. 8.212 de 1991. "Art. 22. A contribuição a cargo da empresa, destinada à Seguridade Social, além do disposto no art. 23, é de: I - vinte por cento sobre o total das remunerações pagas, devidas ou creditadas a qualquer título, durante o mês, aos segurados empregados e trabalhadores avulsos que lhe prestem serviços, destinadas a retribuir o trabalho, qualquer que seja a sua forma, inclusive as gorjetas, os ganhos habituais sob a forma de utilidades e os adiantamentos decorrentes de reajuste salarial, quer pelos serviços efetivamente prestados, quer pelo tempo à disposição do empregador ou tomador de serviços, nos termos da lei ou do contrato ou, ainda, de convenção ou acordo coletivo de trabalho ou sentença normativa». 
social, determina uma alíquota de $15 \%$ no valor da prestação de serviços executada pela cooperativa de trabalho. ${ }^{7}$

A redução do custo fiscal é palmar, fruto de uma alíquota $5 \%$ menor, além do custo da prestação do serviço (base de cálculo) ser inferior aos encargos trabalhistas.

Em virtude dessa conjuntura fática, alhures descrito, ensejou a publicação da Lei n. ${ }^{\circ}$ 12.690, de 19 de julho de 2012, a qual vem dispor sobre a organização das cooperativas de trabalho; instituir o Programa Nacional de Fomento às Cooperativas de Trabalho-PRONACOOP e revogar o parágrafo único do art. 442 da Consolidação das Leis do Trabalho.

É cristalino que o escopo dessa lei foi criar um marco regulatório de forma a especificar os requisitos da licitude que configuraria o serviço prestado por uma cooperativa de trabalho, vindo a coibir o uso das mesmas como subterfúgio fraudulento aos direitos sociais dos trabalhadores.

Fazendo uso de uma metodologia de análise qualitativa e utilizando-se os métodos de abordagem hipotético-dedutivos de caráter descritivo e analítico, buscar-se-á fazer uma apreciação das novidades normativas trazidas pela Lei n. ${ }^{\circ} 12.690 / 12$.

\section{A cooperativa de trabalho (fraudulenta) como instrumento para alijamento dos direitos sociais do empregado}

\subsection{Da cooperativa de trabalho}

Sobre o pálio do Código Civil de 2002, pode-se conceituar as cooperativas como uma pessoa jurídica de direito privado, sendo uma espécie de sociedade simples por determinação legal expressa. ${ }^{8}$ Esse seria um simplório conceito jurídico.

7 Lei n. ${ }^{\circ} 8.212$ de 1991.Art. 22. A contribuição a cargo da empresa, destinada à Seguridade Social, além do disposto no art. 23, é de: ... IV - quinze por cento sobre o valor bruto da nota fiscal ou fatura de prestação de serviços, relativamente a serviços que lhe são prestados por cooperados por intermédio de cooperativas de trabalho.

8 Art. 982. Salvo as exceções expressas, considera-se empresária a sociedade que tem por objeto o exercício de atividade própria de empresário sujeito a registro (art. 967); e, simples, as demais.

Parágrafo único. Independentemente de seu objeto, considera-se empresária a sociedade por ações; e, simples, a cooperativa. 
Segundo a recomendação n. 193 de 2002 da Organização Internacional do Trabalho, cooperativa seria:

Para os efeitos desta Recomendação, o termo «cooperativa» significa associação autônoma de pessoas que se unem voluntariamente para atender a suas necessidades e aspirações comuns, econômicas, sociais e culturais, por meio de empreendimento de propriedade comum e de gestão democrática.

No que tange as cooperativas de trabalho, a Lei $n .^{\circ} 12.690 / 12$ trouxe uma definição legal:

Art. 2. ${ }^{\circ}$ Considera-se Cooperativa de Trabalho a sociedade constituída por trabalhadores para o exercício de suas atividades laborativas ou profissionais com proveito comum, autonomia e autogestão para obterem melhor qualificação, enda, situação socioeconômica e condições gerais de trabalho.

Nessa definição, se extrai, prontamente, que a finalidade da cooperativa é agregar ao trabalhador/sócio uma melhor condição para o exercício de suas atividades, seja no plano econômico, seja no plano das condições fáticas de exercício dessa atividade, o qual, numa relação subordinada de emprego, o mesmo não galgaria. Ou seja, a cooperativa reuniria condições onde o trabalhador granjearia um «plus» não ofertado quando do vínculo de emprego.

O novo dispositivo legislativo explicitou as espécies de cooperativas de trabalho:

Art. $4 .^{\circ}$ A Cooperativa de Trabalho pode ser:

I - de produção, quando constituída por sócios que contribuem com trabalho para a produção em comum de bens e a cooperativa detém, a qualquer título, os meios de produção; e

II - de serviço, quando constituída por sócios para a prestação de serviços especializados a terceiros, sem a presença dos pressupostos da relação de emprega.

A cooperativa de trabalho de produção seria a cooperativa clássica, onde os trabalhadores, reunidos, detêm os meios de produção e, juntos, potencializam seus esforços, de sorte a imperar um sistema de mutualismo entre os mesmos.

Já a cooperativa de trabalho de serviço teria a agremiação de trabalhadores, de uma determinara área ou de áreas afins, com o intento de prestar serviços de forma terceirizada. 
No art. 1094 do Código Civil, tem-se os predicados da cooperativa:

Art. 1.094. São características da sociedade cooperativa:

I - variabilidade, ou dispensa do capital social;

II - concurso de sócios em número mínimo necessário a compor a administração da sociedade, sem limitação de número máximo;

III - limitação do valor da soma de quotas do capital social que cada sócio poderá tomar;

IV - intransferibilidade das quotas do capital a terceiros estranhos à sociedade, ainda que por herança;

$\checkmark$ - quórum, para a assembleia geral funcionar e deliberar, fundado no número de sócios presentes à reunião, e não no capital social representado;

$\mathrm{VI}$ - direito de cada sócio a um só voto nas deliberações, tenha ou não capital a sociedade, e qualquer que seja o valor de sua participação;

VII - distribuição dos resultados, proporcionalmente ao valor das operações efetuadas pelo sócio com a sociedade, podendo ser atribuído juro fixo ao capital realizado;

VIII - indivisibilidade do fundo de reserva entre os sócios, ainda que em caso de dissolução da sociedade.

Destarte, no art. $3 .^{\circ}$ da Lei n. ${ }^{\circ} 12.680 / 12$, são erigidos a tábua axiológica de uma cooperativa de trabalho, a qual se pode aplicar para toda modalidade de cooperativa:

Art. 3. ${ }^{\circ}$ A Cooperativa de Trabalho rege-se pelos seguintes princípios e valores:

I - adesão voluntária e livre;

II - gestão democrática;

III - participação econômica dos membros;

IV - autonomia e independência;

$V$ - educação, formação e informação;

VI - intercooperação;

VII - interesse pela comunidade;

VIII - preservação dos direitos sociais, do valor social do trabalho e da livre iniciativa;

IX - não precarização do trabalho;

$X$ - respeito às decisões de assembleia, observado o disposto nesta Lei;

XI - participação na gestão em todos os níveis de decisão de acordo com o previsto em lei e no Estatuto Social.

Os enunciados do Código Civil e da Lei das cooperativas de trabalho dialogam num mesmo sentir, ou seja, tem-se a criação de uma 
pessoa jurídica de direito privado (sociedade simples), onde esta seria um instrumento provedor de interesses sociais frente ao regime capitalista numa era de globalização, na qual o capital se movimenta em frações de segundos para o mercado de maior lucratividade (capital gerando capital). ${ }^{9}$

Como sociedade, tem-se a reunião de pessoas, as quais aderem de forma voluntária, adquirindo uma quota social, esta intransferível (sociedade de pessoas e não de capital), constituindo sua gestão fruto de uma participação coletiva, onde o voto é por pessoa e não por quantidade de quotas («uma pessoa um voto»), sendo o resultado das operações econômicas distribuído proporcionalmente em função do nível de trabalho ou operação perpetrada pelo sócio.

Portanto, teleologicamente, a cooperativa busca efetivar um conjunto de garantias sociais em prol da dignificação do trabalhador, nos termos dos direitos fundamentais de $2 .^{\circ}$ dimensão, esculpidos na Constituição Federal de 1988. Ter-se-ia uma forma de economia solidária10 fruto de um processo de mitigação dos efeitos deletérios de uma economia de mercado sem regulação. ${ }^{11}$

9 «Na economia de mercado, em que assenta a sociedade do trabalho, as empresas, submetidas a um regime de concorrência intensa, buscam, obstinadamente, o melhor resultado possível de suas atividades. Atingir esse objetivo implica a redução dos custos da produção, que se reflete nos direitos sociais, especialmente os trabalhistas, com a precarização do contrato de trabalho, efetivada por meio de flexibilização e desregulamentação das relações laborais». (Soares Filho, José. Sociedade Pós Industrial. Os impactos da globalização na Sociedade, no Trabalho, na Economia e no Estado. Curitiba: Juruá, 2007, p. 125)

10 «Exemplo típico de empresas de economia social ou solidária são as cooperativas de produção, que, como tais, geram empregos e renda, enquanto produzem efeitos econômicos estruturantes porquanto se tomam empreendimentos sustentáveis. Combinam lógicas sociocoletivas e eficiência empresarial; por conseguinte, operam em relações de mercado e em formas de interação e solidariedade social...». (Soares Filho, José. Sociedade Pós Industrial. Os impactos da globalização na Sociedade, no Trabalho, na Economia e no Estado. Curitiba: Juruá, 2007, p. 127).

11 «A economia solidária representa um meio de produção e distribuição de bens e serviços alternativo ao capitalismo, criado por pessoa: que se encontram marginalizadas, ou excluídas, do mercado formal de trabalho. Compatibiliza o princípio da unidade entre posse e uso dos meios de produção e distribuição com o princípio da socialização dos meios». (Soares Filho, José. Sociedade Pós Industrial. Os impactos da globalização na Sociedade, no Trabalho, na Economia e no Estado. Curitiba: Juruá, 2007, 2007, p. 125). 


\subsection{Dos elementos configuradores da licitude da cooperativa de trabalho}

Em virtude do uso das cooperativas de trabalho de prestação de serviços pelos empresários de formar a dissimular uma efetiva relação empregatícia, a Lei n. ${ }^{\circ} 12.690$, de 2012, traz expresso o que já era sabedor: é ilícito utilizar a cooperativa como intermediária de mão de obra. ${ }^{12}$

Para configurar a licitude da cooperativa, é imprescindível aferir certos elementos, o que lhe dá contornos genuinamente de uma cooperativa.

Primeiramente deve estar presente a dupla qualidade ou condição, por este elemento o trabalhador seria sócio e cliente da cooperativa. ${ }^{13} \mathrm{O}$ u seja, a cooperativa tem por fulcro promover serviços ao sócio/cooperado, pois é criada em função dele. ${ }^{14}$

O princípio da dupla qualidade informa que a pessoa filiada tem de ser, ao mesmo tempo, em sua cooperativa, cooperado e cliente, auferindo as vantagens dessa duplicidade de situações.

Isso significa que, para tal princípio, é necessário haver efetiva prestação de serviços pela Cooperativa diretamente ao associado - e não somente a terceiros. Essa prestação direta de serviços aos associados/cooperados é, aliás, conduta que resulta imperativamente da própria Lei de Cooperativas (art. 6. ${ }^{\circ}$, I, Lei n. 5.764/70). ${ }^{15}$

12 Lei n. ${ }^{\circ} 12.690 / 12$. Art. 5. ${ }^{\circ}$ A Cooperativa de Trabalho não pode ser utilizada para intermediação de mão de obra subordinada.

13 «... Cumpre lembrar que o verdadeiro cooperado apresenta uma dupla condição em relação à cooperativa, pois, além de prestar serviços, deverá ser beneficiário dos serviços prestados pela entidade». (Monteiro de Barros, Alice. Curso do Direito do Trabalho. $7^{\circ}$ ed. São Paulo: LTr, 2011, p. 183)

14 Lei n. ${ }^{\circ}$ 5.764/71. Art. $4 .^{\circ}$ As cooperativas são sociedades de pessoas, com forma e natureza jurídica próprias, de natureza civil, não sujeitas a falência, constituídas para prestar serviços aos associados, distinguindo-se das demais sociedades pelas seguintes características:

Art. 7. ${ }^{\circ}$ As cooperativas singulares se caracterizam pela prestação direta de serviços aos associados.

«Objetiva, desse modo, o princípio da dupla qualidade que as cooperativas destaquem-se por uma peculiaridade em face de outras associações: o próprio associado é um dos beneficiários centrais dos serviços por ela prestados» (grifos nosso). (Godinho Delgado, Mauricio. Curso do Direito do Trabalho. 10. ${ }^{\circ}$ ed. São Paulo: LTr, 2011, p. 328). Cf. Bomfim Cassar, Vólia. Direito do Trabalho. 5. ed. Rio de Janeiro: Impetus, 2011, p. 331.

15 Godinho Delgado, Mauricio. Curso do Direito do Trabalho. $10{ }^{\circ}$ ed. São Paulo: LTr, 2011, p. 328. 
Constatando, no caso concreto, que as operações dessa cooperativa resumem-se, tão somente, a prestar serviços a terceiros, olvidando qualquer atividade em prol do sócio/cooperado, ter-se-ia uma típica situação de intermediação de mão de obra, via cooperativa.

Como a natureza da cooperativa é a de uma sociedade simples, são imprescindíveis, para a concepção de qualquer sociedade, os requisitos da pluralidade de sócios e do affectio societatis. ${ }^{16}$

Esse affectio societatis seria a manifestação de vontade, a intenção, o querer se reunir em sociedade. ${ }^{17}$ Quando certas empresas obrigam o trabalhador a se associar à cooperativa como requisito da sua contração, por óbvio que a validade da construção dessa cooperativa está maculada ${ }^{18}$ bem como estão maculadas as relações dela decorrentes. ${ }^{19}$

Como citado outrora, a cooperativa tem em sua essência uma administração promovida por uma gestão democrática, que congrega a participação dos sócios/cooperados nas tomadas de decisões. ${ }^{20}$

16 Cf. Requião, Rubens. Curso de direito comercial. 30. ed. São Paulo: Saraiva, 2011. V. I, p. 461.

17 «É uma antiga expressão latina, usada por Ulpiano, para distinguir a intenção de se associar em sociedade. Os autores têm procurado desvendar o verdadeiro sentido da expressão, tendo Thaller divisado nela «um elo de colaboração ativa entre os sócios»...

.... o Prof. Lagarde prefere dizer que a affectio societatis é caracterizada por uma vontade de união e aceitação das áleas comuns.

Esse elemento característico do contrato societário é altamente útil na prática da vida comercial, para distinguir a sociedade de outros tipos de contrato, que tendem a se confundir, aparentemente, com a sociedade de fato ou presumida. O conceito é subjetivo, o elemento é intencional, e se deve perquirir dos reflexos aparentes e exteriores, se a intenção do agente foi de unir seus esforços para obter resultados comuns, que isoladamente não seriam tão plenamente conseguidos. ...» (Requião, Rubens. Curso de Direito Comercial. $30{ }^{\circ}$ ed. São Paulo: Saraiva, 2011. V. I, p. 468-469).

18 «... O cooperado é um trabalhador autônomo e, por conta disso, não pode ter a sua atividade dirigida por outra pessoa, seja o diretor da cooperativa, seja o responsável da empresa tomadora dos serviços oferecidos por essa entidade». (Cairo Jr., José.

Curso do Direito do Trabalho. 6. ${ }^{\circ}$ ed. Salvador: Juspodivm, 2011, p. 151-152).

19 «A voluntariedade impõe que ninguém possa ser obrigado a aderir a uma cooperativa, ou seja, que só seja legítima a adesão a uma cooperativa se for voluntária. Mas a voluntariedade não se esgota no momento da adesão. Pelo contrário, tem que estar presente durante todo o tempo em que haja uma relação de pertença de cada cooperador (cuja vontade se tem que permanentemente respeitar) à cooperativa.

Este aspecto do princípio tem especial importância, por exemplo, como garantia de que um regime autoritário não possa, legitimamente, forçar as pessoas a serem membros de uma cooperativa». (Namorado, Rui. Cooperatividade e Direito Cooperativo: estudos e pareceres. Coimbra: Almedina, 2005, p. 20).

20 Este funcionamento democrático implica a sua participação activa na vida da cooperativa. Uma participação que compreende expressamente o envolvimento dos cooperadores na formulação das políticas da cooperativa, bem como na tomada de deci- 
De tal sorte, constatando in loco que na cooperativa de trabalho não há registro de atas das assembleias, ou que há apenas ata da assembleia de constituição da cooperativa, ou que as mesmas são raríssimas em face do tempo de existência da cooperativa, ${ }^{21}$ tem-se uma instituição fraudulenta que está intermediando mão de obra.

Atente que, sem assembleias periódicas, não há uma gestão participativa na cooperativa, sendo as tomadas de decisões sobre o trilhar dessa sociedade tomada por um verdadeiro «chefe/patrão», o que perverte o conceito e a missão de cooperativa.

Gize-se que os trabalhadores se reúnem em cooperativa com o propósito de melhorar sua condição de trabalho, vindo a potencializar seus ganhos econômicos, tendo uma retribuição pessoal diferenciada.

De fato, o que justifica a existência da cooperativa - e as vantagens que essa figura recebe da ordem jurídica - é a circunstância de que ela potencia as atividades humanas e das organizações cooperadas. As cooperativas são protegidas pelo Direito porque potenciam o trabalho humano.

Efetivamente, a cooperativa permite que o cooperado obtenha uma retribuição pessoal, em virtude de sua atividade autônoma, superior àquilo que obteria caso não estivesse associado. A retribuição pessoal de cada cooperado é, necessariamente (ainda que em potencial), superior àquela alcançada caso atuando isoladamente. ${ }^{22}$

sões. Assim se dá um sentido participativo à democracia cooperativa. (Namorado, Rui. Cooperatividade e Direito Cooperativo: estudos e pareceres. Coimbra: Almedina, 2005, p. 23).

21 Exemplo: a cooperativa existe há 5 anos e só consta? a realização de três assembleias.

22 Godinho Delgado, Mauricio. Curso do Direito do Trabalho. $10{ }^{\circ}$ ed. São Paulo: LTr, 2011, p. 329. "Observe-se, ilustrativamente, como atua o princípio da retribuição pessoal diferenciada na prática do mercado econômico. Tome-se o caso de uma cooperativa de condutores autônomos de táxis. A ação da cooperativa tende a conferir ao cooperado, que já atua como profissional autônomo, um amplo e diferenciado complexo de vantagens de natureza diversa: ela amplia o mercado do cooperado, fazendo convênios com empresas, instituindo sistema de teletáxi, etc.; ela captura no sistema institucional linhas de financiamento favorecido para seus associados; ela subsidia o combustível e peças de reposição para os taxistas filiados; ela subscreve convênios diversos para os taxistas e seus dependentes, etc. O mesmo pode ocorrer com cooperativas de serviços de médicos autônomos: o cooperado médico, que já labora como profissional autônomo, aufere, em função do cooperativismo, clientela específica, certa e larga - clientela inimaginável caso ele estivesse atuando sozinho, isolado em seu consultório; além disso, a cooperativa presta-lhe diversos outros serviços, ampliando seu potencial». (Godinho Delgado, Mauricio. Curso do Direito do Trabalho. 10. ${ }^{\circ}$ ed. São Paulo: LTr, 2011, p. 329). 
Quando de um processo fiscalizatório, vindo um auditor fiscal do trabalho ${ }^{23}$ averiguar que o sócio/cooperado realiza um serviço no qual o mesmo não aufere uma vantagem, um «plus», pelo contrário, está numa situação social inferior daquele que exerce o trabalho autônomo ou como um efetivo empregado, infere pelo desvio de finalidade dessa cooperativa.

Afinal, vislumbra-se a constituição de uma cooperativa como fraudulenta quando da inexistência de capital próprio da cooperativa, ou seja, se a cooperativa não é detentora dos meios de produção, mas sim, terceiros, que tomam o serviço da cooperativa, esta não passa de uma intermediadora.

Do mesmo modo, tem-se essa ilicitude quando da divisão não isonômica dos resultados, sejam eles positivos ou negativos. Principalmente, no caso do não repasse dos prejuízos aos sócios/cooperados, afere que os mesmos não são os responsáveis pelos riscos da atividade, sendo esta suportada por terceiro, vindo isso a configurar uma subordinação, sobrepujando qualquer ideário cooperativista.

Noutro falar, configurado fraude a constituição das cooperativas, ter-se-á a formação do vínculo de emprego entre a empresa tomadora do serviço e o pseudo-sócio/cooperado. Assim são os termos da súmula 331, I do Tribunal Superior do Trabalho:

Súmula n. ${ }^{\circ} 331$ do Tribunal Superior do Trabalho

CONTRATO DE PRESTAÇÃO DE SERVIÇOS. LEGALIDADE (nova redação do item IV e inseridos os itens $\mathrm{V}$ e VI à redação)

I - A contratação de trabalhadores por empresa interposta é ilegal, formando-se o vínculo diretamente com o tomador dos serviços, salvo no caso de trabalho temporário (Lei n. ${ }^{\circ} 6.019$, de 03.01.1974).

Diversas são as decisões do Tribunal Superior do Trabalho onde se reconheceu o uso de cooperativas de trabalho como forma de intermediação de mão de obra:

AGRAVO DE INSTRUMENTO. RECURSO DE REVISTA - DESCABIMENTO. 1. CONTRATAÇÃO DE TRABALHADOR POR EMPRESA INTERPOSTA - COOPERATIVA - FRAUDE - RECONHECIMENTO DE RELA-

23 Art. $1 .^{\circ}$ da Portaria N. ${ }^{\circ}$ 925, de 28 de Setembro de 1995. Art. 1.० O Agente da Inspeção do Trabalho, quando da fiscalização na empresa tomadora de serviços de sociedade cooperativa, no meio urbano ou rural, procederá ao levantamento físico, objetivando detectar a existência dos requisitos da relação de emprego entre a empresa tomadora e os cooperados, nos termos do art. 3. ${ }^{\circ}$ da CLT. 
ÇÃO DE EMPREGO DIRETAMENTE COM O TOMADOR DE SERVIÇOS. Decisão regional que acolhe a compreensão da Súmula 331, I, desta Corte, não desafia recurso de revista nos termos da Súmula 333/Tribunal Superior do Trabalho e do art. 896, § 4², da Consolidação das Leis do Trabalho ...

Diante das evidências patentes que o caso versa sobre terceirização ilícita, vez que a atividade-fim, e não a atividade-meio da demandada era exercida por terceiros. A fraude é pois manifesta considerando que a demandante foi contratada para exercer a função de coletora de dados, função essa que era remunerada, e exercida com pessoalidade e subordinação, se revelando assim inútil a tentativa da recorrente de comprovar o contrário, afastando-se da prova produzida, preferindo apontar, sem qualquer razão violação a um sem número de artigos legais e constitucionais impertinentes, que não guardam relação com o que se discute, ficando desde já refutada a aplicabilidade daquele, bem como da Súmula n. ${ }^{\circ} 331$ do Tribunal Superior do Trabalho, porque a hipótese não versa sobre atividade meio, como enganosamente quer fazer crer a recorrente, como já ressaltado.

A recorrente se utiliza de mão de obra terceirizada para prestar serviços ligados à sua atividade-fim, contratando falsas cooperativas, com o só fim de burlar a lei. Tal procedimento, entretanto, não passa pelo crivo do artigo $9 .^{\circ}$ consolidado.

A pretensão de dar à relação de emprego roupagem diversa, por meio de documentos nos quais a reclamante figure como cooperada, cede diante de um dos princípios mais caros ao Direito do Trabalho, qual seja o da primazia da realidade, que prioriza o que sucede no terreno dos fatos.

Assim, como se trata de atividade-fim do tomador de serviços, há que se considerar ilícita a terceirização, cabendo ressaltar que o ordenamento jurídico pátrio só a admite na hipótese de trabalho temporário para cobrir acréscimo extraordinário de serviço ou substituição de pessoal permanente, o que não é a hipótese dos autos tendo em vista a não observância da formalidade exigida pela Lei n. ${ }^{\circ}$ 6.019/74, bem como com relação àqueles trabalhadores regidos pela Lei n. ${ }^{\circ}$ 7.102/83, concernente ao serviço de vigilância, situações diversas do que aqui se discute. ${ }^{24}$ (Grifos nossos)

24 Tribunal Superior do Trabalho. TERCEIRA TURMA, AIRR - 46440-06.2008.5. 01.0007, rel. Min. Alberto Luiz Bresciani de Fontan Pereira, Diário Eletrônico da Justiça do Trabalho, 20/04/2010. 
Em outro julgado, recente:

VÍNCULO DE EMPREGO. EMPRESA DE TELECOMUNICAÇÕES. HIPÓTESE DE CONTRATAÇÃO MEDIANTE COOPERATIVA. FRAUDE. TERCEIRIZAÇÃO ILÍCITA. SUBORDINAÇÃO DIRETA À TOMADORA DOS SERVIÇOS.

1. Constatando-se que a reclamante foi contratada mediante cooperativa considerada fraudulenta, não há falar em terceirização lícita nos moldes da Lei Geral das Telecomunicações - Lei n. ${ }^{\circ} 9.472$ 197. 2. Consoante disposto na Súmula n. ${ }^{\circ} 331$, itens I e III, desta Corte superior, a terceirização ilícita de serviços, caracterizada pela contratação de serviços ligados à atividade-fim mediante empresa interposta ou pela contratação de serviços especializados ligados à atividade-meio, mas prestados com pessoalidade e subordinação direta ao contratante, acarreta o reconhecimento de vínculo de emprego diretamente com o tomador dos serviços. 3. Uma vez consignado expressamente no acórdão prolatado pelo Tribunal Regional que a reclamante prestava serviços de forma exclusiva, relacionada à atividade fim da TELEMAR —-tomadora dos serviços-, resulta evidenciada a ilicitude da terceirização havida, visto que configurado o intuito de fraudar a legislação trabalhista mediante a contratação da obreira por intermediação de cooperativa simulada. Em tais circunstâncias, o vínculo de emprego forma-se diretamente com a tomadora dos serviços, nos termos do verbete sumular transcrito. ${ }^{25}$

\subsection{Requisito formal trazido pela Lei $n .^{\circ} 12.690 / 12$ para licitude da cooperativa de trabalho de prestação de serviço}

Perfilhado o contexto problemático do desvio de finalidade na constituição de cooperativas de trabalho, especificamente da prestadora de serviço, bem como dos elementos materiais que imbricam o desenvolvimento legítimo dessa cooperativa, é aventado um tecido normativo infraconstitucional, por meio da Lei n. ${ }^{\circ}$ 12.690/12, que subscreve um instrumento formal desvelador da licitude ou ilicitude das atividades da cooperativa.

25 Tribunal Superior do Trabalho. PRIMEIRA TURMA, AIRR - 77240-52.2003.5. 06.0007, rel. Min. Lelio Bentes Corrêia, Diário Eletrônico da Justiça do Trabalho, 01/08/2012. 
Assim prescreve o $§ 6 .^{\circ}$ do art. 7. ${ }^{\circ}$ da lei explicitada:

$\S 6 .^{\circ}$ As atividades identificadas com o objeto social da Cooperativa de Trabalho prevista no inciso II do caput do art. $4 .^{\circ}$ desta Lei, quando prestadas fora do estabelecimento da cooperativa, deverão ser submetidas a uma coordenação com mandato nunca superior a 1 (um) ano ou ao prazo estipulado para a realização dessas atividades, eleita em reunião específica pelos sócios que se disponham a realizá-las, em que serão expostos os requisitos para sua consecução, os valores contratados e a retribuição pecuniária de cada sócio partícipe.

O instrumento normativo supra exige que, para a prestação de serviço feita pelos sócios/cooperados de uma cooperativa de serviço fora das dependências da cooperativa, é imprescindível a criação de uma coordenação, a qual terá duração de um ano ou tempo equivalente à prestação de serviço, tendo a mesma a função de determinar, com a participação dos sócios interessados em prestar os serviços, as condições para a execução do mesmo, o valor a ser contratado e a retribuição de cada cooperado.

Durante o exercício das fiscalizações, se o auditor do trabalho identificar, num trabalho realizado por sócios de uma cooperativa de serviço, sendo este executado no interior do estabelecimento empresarial, não sendo constatado a constituição dessa coordenação nos moldes acima descrito, haverá a presunção (relativa) da intermediação da mãode-obra, enunciando uma verdadeira relação empregatícia, nos termos do $§ 2 .^{\circ}$ do art. 17 da lei das cooperativas de trabalho:

$\S 2 .^{\circ}$ Presumir-se-á intermediação de mão de obra subordinada a relação contratual estabelecida entre a empresa contratante e as Cooperativas de Trabalho que não cumprirem o disposto no $\S 6 .^{\circ}$ do art. $7 .^{\circ}$ desta Lei.

\subsection{Composição de um arcabouço de prerrogativas sociais em favor do sócio/cooperativo}

O sócio/cooperado, ao realizar um serviço, seria enquadrado como um trabalhador autônomo, não perfazendo, assim, jus ao largo espectro de direitos sociais cobertos numa relação empregatícia.

Em face disso, justificou a proliferação de cooperativas de trabalho de serviço, como fito de enquadrar um autêntico trabalhador empregado como autônomo para não arcar com os devidos custos sociais. 
Não descuidando da realidade desses sócios/cooperados das cooperativas de serviço, a Lei $n .^{\circ} 12.690 / 12$ introjeta no sistema um grupo de garantias sociais mínimas, anteriormente inexistentes, que se assemelham às dos trabalhadores em relação empregatícia, amparando esses sócios/cooperados.

Portando, assim se delineia o art. $7 .^{\circ}$ da citada lei:

Art. 7. ${ }^{\circ}$ A Cooperativa de Trabalho deve garantir aos sócios os seguintes direitos, além de outros que a Assembleia Geral venha a instituir:

I - retiradas não inferiores ao piso da categoria profissional e, na ausência deste, não inferiores ao salário mínimo, calculadas de forma proporcional às horas trabalhadas ou às atividades desenvolvidas;

II - duração do trabalho normal não superior a 8 (oito) horas diárias e 44 (quarenta e quatro) horas semanais, exceto quando a atividade, por sua natureza, demandar a prestação de trabalho por meio de plantões ou escalas, facultada a compensação de horários:

III - repouso semanal remunerado, preferencialmente aos domingos;

IV - repouso anual remunerado;

$\checkmark$ - retirada para o trabalho noturno superior à do diurno;

$\mathrm{VI}$ - adicional sobre a retirada para as atividades insalubres ou perigosas;

VII - seguro de acidente de trabalho.

Segue um quadro comparativo entre as garantias sociais dos sócios/cooperados, segundo o art. $7 .^{\circ}$ da lei n. ${ }^{\circ} 12.690 / 12$, e as garantias previstas no art. $7 .^{\circ}$ da Constituição Federal de 1988, aplicada nas relações de emprego.

Afere-se que essa tábua de prerrogativas sociais esculpida em prol do sócio/cooperado, assemelhando ou igualando diversos direitos sociais aplicados numa relação de emprego, tem dois intentos específicos: a) dignificar e humanizar o trabalho realizado por esse sócio/ cooperado; b) constituir um arcabouço normativo de caráter indutor, o qual desestimularia a tentativa de fraude nas relações de emprego, ocultada pela fachada de uma cooperativa de trabalho de serviço, tendo em vista que o custo social em relação ao sócio/cooperado seria semelhante ou se aproximaria do custo do trabalhador empregado. 


\begin{tabular}{|c|c|}
\hline SÓCIO/COOPERADO & RELAÇÃO EMPREGATÍCIA \\
\hline Art. $7^{\circ}$ da Lei n. ${ }^{\circ} 12.690$ & Art. 7. da Constituição Federal de 1988 \\
\hline $\begin{array}{l}\text { I - retiradas não inferiores ao piso da } \\
\text { categoria profissional e, na ausência } \\
\text { deste, não inferiores ao salário mínimo, } \\
\text { calculadas de forma proporcional às ho- } \\
\text { ras trabalhadas ou às atividades desen- } \\
\text { volvidas; }\end{array}$ & $\begin{array}{l}\text { V - piso salarial proporcional à exten- } \\
\text { são e à complexidade do trabalho; } \\
\text { VII - garantia de salário, nunca inferior } \\
\text { ao mínimo, para os que percebem re- } \\
\text { muneração variável; }\end{array}$ \\
\hline $\begin{array}{l}\text { II - duração do trabalho normal não } \\
\text { superior a } 8 \text { (oito) horas diárias e } 44 \\
\text { (quarenta e quatro) horas semanais, ex- } \\
\text { ceto quando a atividade, por sua natu- } \\
\text { reza, demandar a prestação de trabalho } \\
\text { por meio de plantões ou escalas, facul- } \\
\text { tada a compensação de horários; }\end{array}$ & $\begin{array}{l}\text { XIII - duração do trabalho normal não } \\
\text { superior a oito horas diárias e quarenta } \\
\text { e quatro semanais, facultada a compen- } \\
\text { sação de horários e a redução da jor- } \\
\text { nada, mediante acordo ou convenção } \\
\text { coletiva de trabalho; }\end{array}$ \\
\hline $\begin{array}{l}\text { III - repouso semanal remunerado, } \\
\text { preferencialmente aos domingos; }\end{array}$ & $\begin{array}{l}\text { XV - repouso semanal remunerado, } \\
\text { preferencialmente aos domingos; }\end{array}$ \\
\hline IV - repouso anual remunerado; & $\begin{array}{l}\text { XVII - gozo de férias anuais remunera- } \\
\text { das com, pelo menos, um terço a mais } \\
\text { do que o salário normal; }\end{array}$ \\
\hline $\begin{array}{l}\text { V - retirada para o trabalho noturno } \\
\text { superior à do diurno; }\end{array}$ & $\begin{array}{l}\text { IX - remuneração do trabalho noturno } \\
\text { superior à do diurno; }\end{array}$ \\
\hline $\begin{array}{l}\mathrm{VI} \text { - adicional sobre a retirada para as } \\
\text { atividades insalubres ou perigosas; }\end{array}$ & $\begin{array}{l}\text { XXIII - adicional de remuneração para } \\
\text { as atividades penosas, insalubres ou pe- } \\
\text { rigosas, na forma da lei; }\end{array}$ \\
\hline VII - seguro de acidente de trabalho. & $\begin{array}{l}\text { XXVIII - seguro contra acidentes de } \\
\text { trabalho, a cargo do empregador, sem } \\
\text { excluir a indenização a que este está } \\
\text { obrigado, quando incorrer em dolo ou } \\
\text { culpa; }\end{array}$ \\
\hline
\end{tabular}

\section{Considerações finais}

A criação e a promoção dos direitos sociais vêm de um longo processo de revoluções, questionamentos, pleitos, com o intuito de gerar a igualdade e dignificar a pessoa através do seu trabalho, que lhe impulsione a um processo de desenvolvimento e crescimento, em todos os aspectos. 
Nessa plêiade houve o surgimento de economias solidárias, entre elas destaca-se a figura de cooperativas, as quais teriam a missão de equilibrar a busca de lucro da economia de mercado em relação ao desenvolvimento social dos trabalhadores.

Todavia, distorções são perpetradas no mundo dos fatos com o intento de "malferir» a pessoa do trabalhador de todo um contexto de direitos básicos num processo de mera mercandajem da mão de obra, chancelando a coisificação da «pessoa humana».

É nessa toada que cooperativas de trabalho de serviço são constituídas, muitas vezes, como entidades intermediadoras de mão de obra, com o desiderato de mascarar uma real relação de emprego (pessoal, subordinada, não eventual, mediante remuneração) para desacobertar o trabalhador de todo o arcabouço de direitos fundamentais previsto na Constituição, reduzindo o custo social do empresário que contrata o serviço da "cooperativa» e compondo uma situação de extrema prejudicialidade ao trabalhador, pois não está auferindo a ele os frutos e as potencialidades de uma legítima cooperativa e nem protegendo-o pelos baluartes jungidos na relação de emprego.

A Lei n. ${ }^{\circ} 12.690 / 12$, nessa conjuntura, tem por preceito teleológico inserir uma moldura normativa capaz de desestimular e coibir a utilização de cooperativas como intermediária de mão de obra, desenhando de forma palmar os elementos que constituem uma cooperativa lícita, além de inovar ao estruturar suportes mínimos aos sócios/cooperados das cooperativas de trabalho, semelhante («quase igual») aos direitos sociais dos trabalhadores em relação de emprego.

É ululante que essa estrutura mínima/básica de prerrogativas sociais vem por dignificar, humanizar, a figura do homem em suas relações de trabalho, quando realizada no seio de cooperativas de trabalho. ${ }^{26}$

26 «Dentre os fatores de equilíbrio de natureza objetiva nas relações de trabalho, tendo em vista o processo de flexibilização destas, menciona-se «a concepção da economia social de mercado, que não só aprecia este último, mas também enfatizo a presença do ser humano e da comunidade como ponto de partida e destinatário da política econômica». Os fatores de natureza subjetiva resultam das atitudes e ocasiões que favorecem o diálogo, o respeito dos direitos humanos, do sistema democrático e pluralista, do direito de associação, de uma cultura do diálogo, da participação, da superação de oposições excludentes, do vislumbrar a possibilidade de reformas dentro de um quadro de estabilidade, do admitir o direito à informação, ao apoio técnico indispensável. Trata-se de promover ações conjuntas a fim de obter benefícios compartilhados em áreas de interesse comum». (Soares Filho, José. Sociedade Pós Industrial. Os impactos da globalização na Sociedade, no Trabalho, na Economia e no Estado. Curitiba: Juruá, 2007, p. 125). 


\section{Referências}

Bomfim CASSAR, Vólia. Direito do Trabalho. 5. ed. Rio de Janeiro: Impetus, 2011.

CAIRo Jr., José. Curso do Direito do Trabalho. 6. ${ }^{\circ}$ ed. Salvador: Juspodivm, 2011.

Godinho Delgado, Mauricio. Curso do Direito do Trabalho. 10. ed. São Paulo: LTr, 2008.

MonteIRo de Barros, Alice. Curso do Direito do Trabalho. 7. ${ }^{\circ}$ ed. São Paulo: LTr, 2011.

NAMORADO, Rui. Cooperatividade e Direito Cooperativo: estudos e pareceres. Coimbra: Almedina, 2005.

Requião, Rubens. Curso de Direito Comercial. 30. ${ }^{\circ}$ ed. São Paulo: Saraiva, 2011. V. I.

SOARES FilHo, José. Sociedade Pós Industrial. Os impactos da globalização na Sociedade, no Trabalho, na Economia e no Estado. Curitiba: Juruá, 2007. 